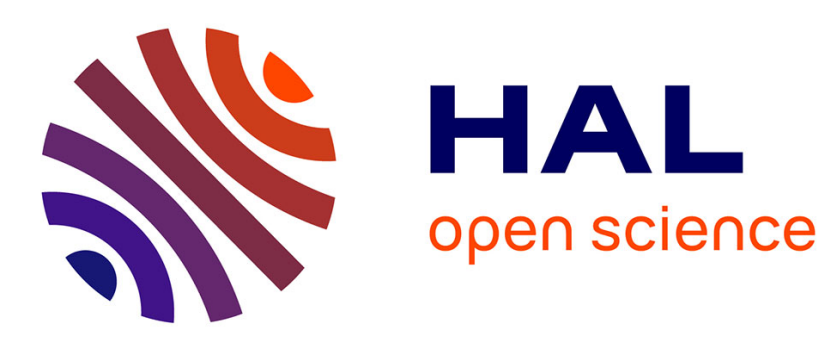

\title{
Real-Time Radio Signal Mapping using an Autonomous Robot
}

\author{
Jean-Mickaël Lebreton, Nour Murad, Richard Lorion
}

\section{To cite this version:}

Jean-Mickaël Lebreton, Nour Murad, Richard Lorion. Real-Time Radio Signal Mapping using an Autonomous Robot. IEEE Radio and Antenna Days of the Indian Ocean, http://radiosociety.org/, Sep 2015, Port Louis, Mauritius. hal-01345673

\section{HAL Id: hal-01345673 https://hal.science/hal-01345673}

Submitted on 10 Nov 2017

HAL is a multi-disciplinary open access archive for the deposit and dissemination of scientific research documents, whether they are published or not. The documents may come from teaching and research institutions in France or abroad, or from public or private research centers.
L'archive ouverte pluridisciplinaire HAL, est destinée au dépôt et à la diffusion de documents scientifiques de niveau recherche, publiés ou non, émanant des établissements d'enseignement et de recherche français ou étrangers, des laboratoires publics ou privés. 


\title{
Real-Time Radio Signal Mapping using an Autonomous Robot
}

\author{
Jean Mickael Lebreton, Nour Murad and Richard Lorion \\ Laboratory of Energetic, Electronic and Processes (LE2P) \\ University of La Reunion \\ Saint-Pierre, France \\ Email: jean.lebreton@univ-reunion.fr
}

\begin{abstract}
A measurement technique for an indoor/outdoor radio signal mapping based on remote sensing through a mobile robot is provided. The robot is autonomous and able to provide its actual location in relation to its initial position. The data are sent in real time to the base station using wireless transmission and the electromagnetic mapping is obtained in real time as well. A real case scenario is considered by measuring the electromagnetic field from our department network. The automated system gives consistent results since it shows highest energy levels next to the sources. This papers shows that a robot can remotely make a precise radio signal mapping of an unknown environment.
\end{abstract}

\section{INTRODUCTION}

Radio signal strength mapping is generally realized in wireless site surveys in order to monitor the coverage of a wireless network. Systems and methods for surveying a wireless network site are presented in [1]. The radio frequency (RF) coverage is generally based on measurement done by a mobile human user. The measurements consist of repetitive tasks which are time consuming and can lead to measuring errors regarding the coordinate information. Other measurement campaigns are done with sensor nodes placed on transport vehicles such as [2], however this method does not enable a controllable path by the sensor node itself.

This article proposes a measurement technique to avoid these disadvantages by using an autonomous mobile robot. Besides, measurements are done for different positions since the robot can move inside an environment and record its path. The data are transferred in real-time to the base station (BS) using a wireless transmission. Then the user can watch in real time the actual position of the robot and the data exploitation. The advantages of this method are the fact that measurements are done in an autonomous way and the mapping is done in real time. The user's presence on the site is only needed at the beginning of the measurement process.

Moreover, electromagnetic mapping can be used to find and identify the different electromagnetic sources available in the environment. This automated system can then be exploited for other projects which aim at harvesting RF energy. Jabbar presents the overview and progress achieved in RF energy harvesting field in [3]. The automated system can also produce RSSI fingerprinting of an area, which is used for WiFi localisation in some studies [4],[5]. Our main contribution is the automation of the RF mapping by a robot and the RF distribution can be viewed in real time.

\section{PRinciple AND Algorithm}

The RF mapping principle is to let the robot move within a defined area and to frequently make a scan of the available RF signals. The algorithm used by the robot is defined in figure 1 .

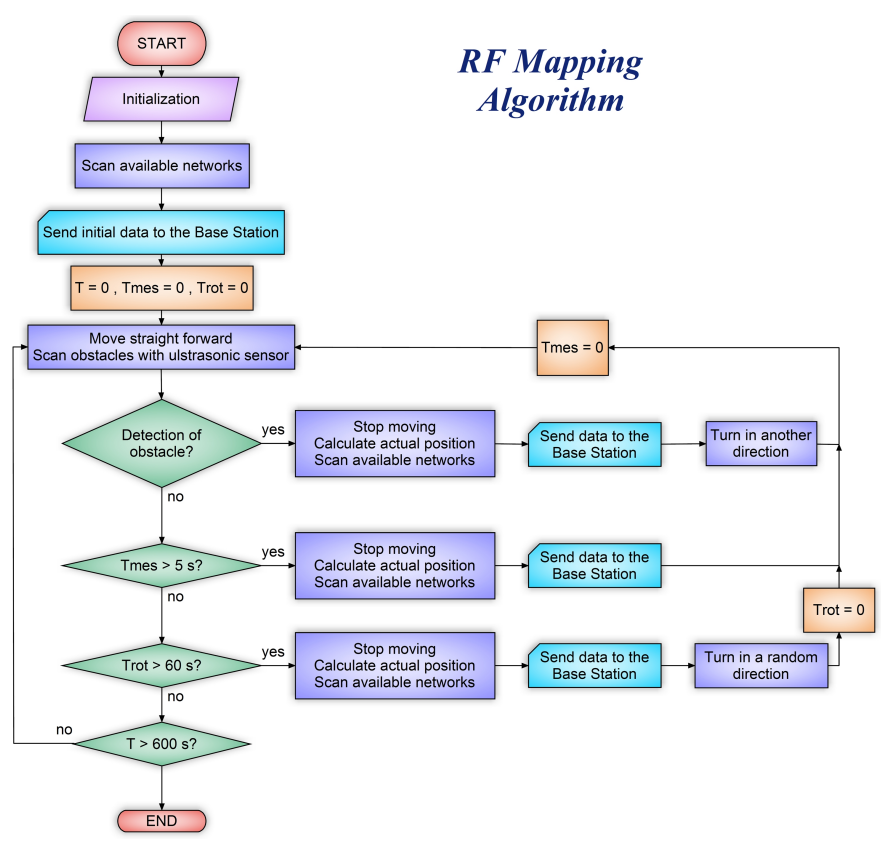

Fig. 1. Flowchart of the algorithm used by the robot to perform a RF mapping of an area.

\section{RESUlTS AND Discussion}

A RF mapping of our department has been done. The floor plan is illustrated in Figure 2 and the access points locations are represented as well. The network deployment and configuration have been done by the department and no specific change is done for the measurement process in order to study the network state. The results are presented in figure 3 , which shows the mapping obtained after 45 minutes of operating time. The robot moved along the corridor of the building and the path is represented in the upper-left subfigure. At each point, the robot measured the received signal strength (RSSI) from five access points. The measured data 


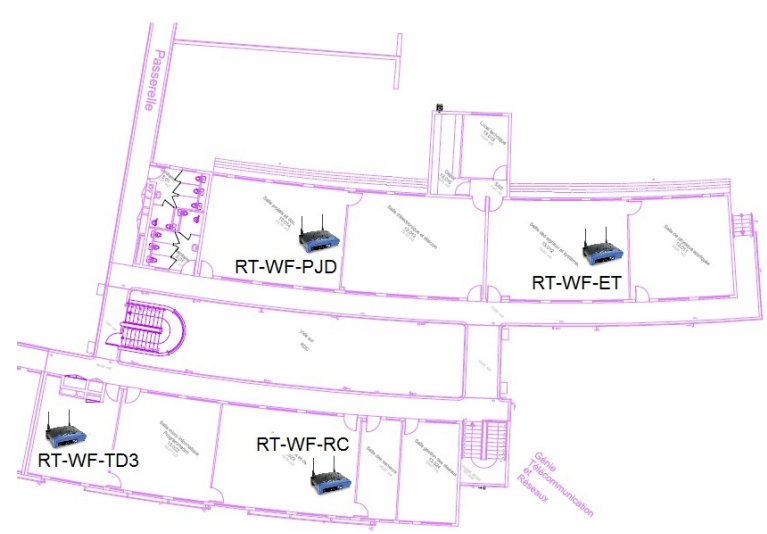

Fig. 2. Floor plan of the department with the access points location.

are related to the close access points since the five highest signal strengths are considered.

Besides, the robot travelled within an area of 40 meters by 10 meters. It was located upstairs, so the measurements could not be done in the middle of the area. The signal strengths are only represented in the corridor even if an extrapolation can be done to show the global evolution of the RSSI in the total area. The RSSI distribution related to the different sources is represented in figure 3. It shows a reliable mapping for first three sources, which were the closest acess points to the robot path. For all of them, the RSSI distribution is consistent since high signal strengths are observed next to the related access point locations. The same signal strength levels are also obtained from these sources, which is consistent with their location toward the robot path. Then, some data have been collected for two other sources, but they were not close enough to get a reliable map. Therefore, the robot can carry out a good RF mapping of a network in a real case study. The entire mapping process can be viewed in [6].

\section{APPLICATION TO PROPAGATION MODEL CHARACTERIZATION}

The radio signal propagation is studied according to the log-normal path loss model [7]:

$$
P_{d B m}=P_{0}-10 n \log \left(\left\|X-X_{s}\right\|\right)+Z_{\sigma}
$$

where $P_{0}$ is the received power at 1 meter from the source, $n$ is the path loss exponent, $X$ and $X_{s}$ are respectively the positions of the receiver and transceiver, $Z_{\sigma}$ is a normally distributed variable with a standard deviation $\sigma$ and a zero-mean value, which represents the random shadowing effects.

A least-square method is applied to the signal strength model and the measures from the radio signal mapping in order to estimate $P_{0}$ and $n$. We are then able to calculate the standard deviation $\sigma$ by using equation 1 . The results are given in table I.

\section{CONClusion AND PERSPECTIVE}

This paper shows that a precise electromagnetic mapping can be achieved by an autonomous robot. As our project is

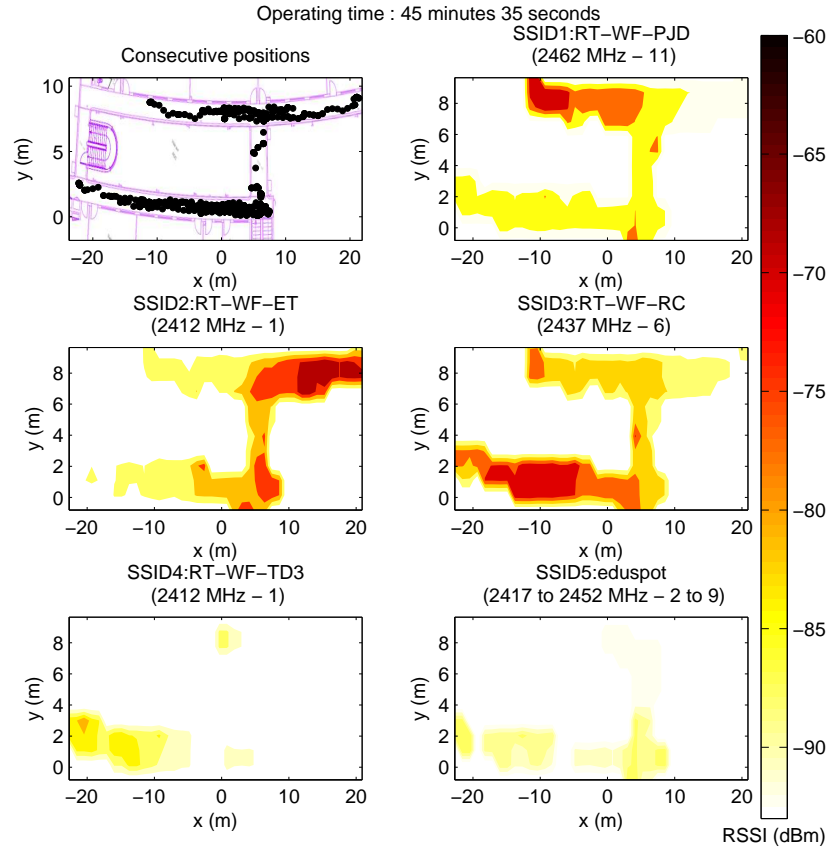

Fig. 3. RF mapping of the department obtained after 45 minutes of measurement.

TABLE I

PARAMETERS ESTIMATION

\begin{tabular}{|c|c|c|c|}
\hline Environment & $P_{0}(d B m)$ & $n$ & $\sigma$ \\
\hline Corridor & -53.6 & 2.3 & 5.7 \\
\hline
\end{tabular}

concerned by RF energy harvesting, the map provided by the robot depicts the location where the most energy is available. It is useful for a future network deployment of nodes with energy harvesting capabilities. Besides, the electromagnetic mapping is done in real time and with an automated system.

\section{REFERENCES}

[1] S.E. Hrastar, "Systems and methods for wireless network site survey", U.S. Patent no. 7522908, Apr. 2009

[2] D. Hasenfratz, S. Sturzenegger, O. Saukh and L. Thiele, "Spatially Resolved Monitoring of Radio-Frequency Electromagnetic Field", ACM Press, pp. 1-6, 2013.

[3] H. Jabbar, Y.S. Song, and T.T. Jeong, "RF energy harvesting system and circuits for charging of mobile devices", Consumer Electronics, IEEE Transaction on, vol. 56, pp. 247-253, Feb. 2010.

[4] J. Biswas, and M. Veloso, "Wifi localization and navigation for autonoum indoor mobile robots", Robotics and Automation (ICRA), 2010 IEEE International Conference on, May 2010, pp. 4379-4384.

[5] M.N. Husen, and S. Lee, "Indoor Human Localization with Orientation using WiFi Fingerprinting", Proceedings of the 8th International Conference on Ubiquitous Information Management and Communication, pp. 109-114, 2014.

[6] J. Lebreton, "Real time visualization of the RF mapping in the R\&T department (32x speed)", accessed December 15, 2014, https://www.youtube.com/watch?v=zh-WkN14Tpw, Oct. 2014.

[7] J. Vallet, O. Kaltiokallo, J. Saarinen, M. Myrsky, and M. Bocca, "On the sensitivity of RSS based localization using the log-normal model: An empirical study", $10^{\text {th }}$ IEEE Workshop on Positioning Navigation and Communication (WPNC) , pp. 1-6, 2013. 